\title{
Microbial Transformations of 3-methoxyflavone by Strains of Aspergillus niger
}

\author{
EDYTA KOSTRZEWA-SUSŁOW*, MONIKA DYMARSKA and TOMASZ JANECZKO
}

Department of Chemistry, Wrocław University of Environmental and Life Sciences

Submitted 15 July 2013, revised 13 November 2013, accepted 16 November 2013

Abstract

\begin{abstract}
Microbial transformation of 3-methoxyflavone into 3'-hydroxyflavon-3-yloxymethyl myristate was presented. Six filamentous fungi were used as biocatalysts: a wild strain of Aspergillus niger KB, its four UV mutants (A. niger MB, SBP, SBJ, 13/5) and the strain of Penicillium chermesinum 113. The highest yields were observed for the strains of A. niger KB and A. niger SBP (69.8\% and 63.1\%, respectively).
\end{abstract}

Ke y words: Aspergillus niger, Penicillium chermesinum, biotransformation, 3-methoxyflavone, myristic acid

Microbial transformation of flavonoid compounds is a natural method which may be a green alternative to chemical synthesis. Using biotransformation we can modify structures of compounds in order to improve their biological properties and to increase their hydrophilicity or bioaccessibility (Das and Rosazza, 2006; Wang et al., 2010).

Regioselective $O$-demethylation of tangeretin and 3-hydroxytangeretin by Aspergillus niger gave 4'-O-demethylated biotransformation products (Buisson et al., 2007) while transformations of 7,8-dimethoxyflavone by Mucor ramannianus gave five biotransformation products involving hydroxylation at C-3' and C-4' with the methoxyl groups retained and products of hydroxylation in the B-ring along with demethylation at C-7 or/and C-8 (Herath et al., 2009).

This manuscript reports the microbial demethylation of 3-methoxyflavone by strains of Aspergillus and Penicillium, followed by non-typical esterification with a fatty acid and hydroxylation in the B-ring.

The analytical procedures were as described previously (Kostrzewa-Susłow and Janeczko, 2012a; 2012b).

The substrate for biotransformation - 3-methoxyflavone was purchased from Sigma-Aldrich, Poznań, Poland.

3-Methoxyflavone $\left(\mathrm{C}_{30} \mathrm{H}_{38} \mathrm{O}_{6}\right)$ : M.p. $114-115^{\circ} \mathrm{C}$. Rt $19.35 \mathrm{~min}$ (HPLC).

${ }^{1} \mathrm{H}$ NMR (DMSO-d $\left.\mathrm{d}_{6}\right) \delta: 3.81\left(3 \mathrm{H}, \mathrm{s},-\mathrm{OCH}_{3}\right), 7.49(1 \mathrm{H}, \mathrm{t}$, $\left.J_{6.5}=8.0, J_{6.7}=7,0 \mathrm{~Hz}, \mathrm{H}-6\right), 7.58$ (3H, m, H-3', H-4, H-5'), $7.75\left(1 \mathrm{H}, \mathrm{d}, J_{8.7}=8.2 \mathrm{~Hz}, \mathrm{H}-8\right), 7.82\left(1 \mathrm{H}, \mathrm{ddd}, J_{7.5}=1.5\right.$, $\left.J_{7.6}=7.0, J_{7.8}=8.2 \mathrm{~Hz}, \mathrm{H}-7\right), 8.05\left(2 \mathrm{H}, \mathrm{m}, \mathrm{H}-2^{\prime}, \mathrm{H}-6^{\prime}\right)$, $8.10\left(1 \mathrm{H}, \mathrm{dd}, J_{5.6}=8.0\right.$, and $\left.J_{5.7}=1.5 \mathrm{~Hz}, \mathrm{H}-5\right) ;{ }^{13} \mathrm{C} \mathrm{NMR}$ (DMSO-d6) $\delta: 60.2\left(-\mathrm{OCH}_{3}\right), 119.0(\mathrm{C}-8), 124.1(\mathrm{C}-10)$, 125.4 (C-6), 125.6 (C-5), 128.8 (C-2', C-6'), 129.2 (C-3', C-5'), 131.0 (C-4' ), 131.4 (C-1'), 134.6 (C-7), 141.3 (C-3), 155.3 (C-2 ), 155.5 (C-9), and 174.4 (C-4).

In this research we used a wild strain of $A$. niger $\mathrm{KB}$ and four UV mutants of A. niger (13/5, SBJ, SBP, $\mathrm{MB})$. The KB strain comes from the collection of the Department of Biotechnology and Food Microbiology of Wrocław University of Environmental and Life Sciences (Poland), strain 13/5 comes from the University of Life Sciences in Lublin (Poland) and strains SBJ, SBP and MB come from Wrocław University of Economics (Poland). Microorganisms were maintained on sterilized potato slants at $5^{\circ} \mathrm{C}$. The wild strain of P. chermesinum 113 was obtained from the collection of the Department of Chemistry of Wrocław University of Environmental and Life Sciences (Poland). The microorganism was maintained on Sabouraud $4 \%$ dextrose-agar slopes and freshly subcultured before use in the transformation experiments.

Screening tests and preparative-scale biotransformations were carried out according to the procedure described earlier (Kostrzewa-Susłow and Janeczko, 2012a; 2012b). The spectral data of the product obtained are presented below.

3'-Hydroxyflavon-3-yloxymethyl myristate $\left(\mathrm{C}_{30} \mathrm{H}_{38} \mathrm{O}_{6}\right)$ : Yellow oily liquid. Rt $17.06 \mathrm{~min}$ (HPLC). Purity 97\% (HPLC). HRESI-MS: $m / z=495.1032\left[\mathrm{M}+\mathrm{H}^{+}\right]$; found $495.1026 .{ }^{1} \mathrm{H}$ NMR $\left(\mathrm{DMSO}-\mathrm{d}_{6}\right) \delta: 0.86(3 \mathrm{H}, \mathrm{t}$, $J=7.0 \mathrm{~Hz}, 13$ " $\left.-\mathrm{CH}_{3}\right), 1.229-1.231$ (14H, m, H-4"-H-10"),

* Corresponding author: E. Kostrzewa-Susłow, Department of Chemistry, Wrocław University of Environmental and Life Sciences, Norwida 25, 50-375 Wrocław, Poland, fax: +48-71-3284124; e-mail: ekostrzew@gmail.com 
1.239-1.261 (6H, m, H-3",11”,12”), 1.55 (2H, tt, J=7.67 $\mathrm{Hz}, \mathrm{H}-2$ "), 2.25 (2H, t, J=7.4 Hz, H-1"), 5.22 (2H, s, O- $\left.\mathrm{CH}_{2}-\mathrm{O}\right), 7.30\left(1 \mathrm{H}, \mathrm{m}, \mathrm{H}-4\right.$ '), $7.39\left(1 \mathrm{H}, \mathrm{ddd}, J_{6.5}=7.9\right.$, $\left.J_{6.7}=7,1 \mathrm{~Hz}, J_{6.8}=1,1 \mathrm{~Hz}, \mathrm{H}-6\right), 7.49$ (3H, m, H-8, 2', 5), $7.66\left(1 \mathrm{H}, \mathrm{ddd}, J_{7.8}=8.4 \mathrm{~Hz}, J_{7.6}=7.1 \mathrm{~Hz}, J_{7.5}=1.7\right.$ $\mathrm{Hz}, \mathrm{H}-7), 7.85$ (1H, m, H-6), 7.91 (1H, s, -OH), and $8.19\left(1 \mathrm{H}, \mathrm{dd}, J_{5.6}=8.0, J_{5.7}=1.7 \mathrm{~Hz}, \mathrm{H}-5\right) .{ }^{13} \mathrm{C} \mathrm{NMR}$

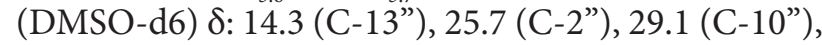
29.3 (C-8”), 29.3 (C-9”), 29.4 (C-7”), 29.5 (C-6”), 29.6 (C-5”), 29.7 (C-4”), 29.8 (C-3”), 30.1 (C-11"), 31.8 (C-12”), 34.1 (C-1"), $83.0\left(\mathrm{O}-\mathrm{CH}_{2}-\mathrm{O}\right), 111.5$ (C-2'), 116.9 (C-4'), 117.3 (C-6'), 119.4 (C-8), 124.2 (C-10), 125.6 (C-6), 125.7 (C-5), 130.0 (C-5'), 132.6 (C-1'), 134.7 (C-7), 149.2 (C-3), 151.0 (C-3’), 155.5 (C-2), 155.7 (C-9), 175.1 (C-4), and $180.8(\mathrm{O}-\mathrm{C}=\mathrm{O})$.

Screening tests revealed six strains of filamentous fungi capable of biotransformation of 3-methoxyfla- vone: a wild strain of $A$. niger $\mathrm{KB}$, its four $\mathrm{UV}$-mutants (A. niger MB, SBP, SBJ, 13/5) and the strain of $P$. chermesinum 113. The initial study was performed according to two procedures: in the first the substrate was added to the cultivation media at the time of inoculation with the microorganism, whereas in the second, it was added 72 hours after the inoculation. After 3, 6 and 9 days samples were analyzed for product and unreacted substrate (Table I, II). All of the tested strains of Aspergillus transformed 3-methoxyflavone into 3'-hydroxyflavon3-yloxymethyl myristate, using either cultivation procedure. P. chermesinum 113 was also capable of this transformation, but only when the substrate was added to the cultivation media in the last phase of logarithmic growth of the mycelium (Table II). For all of the tested Aspergillus strains the biotransformation was more efficient when the substrate was added to the cultivation

Table I

Biotransformation of 3-methoxyflavone (substrate added at the time of inoculation) - yield (\%) of product determined by HPLC

\begin{tabular}{|c|l|c|c|c|}
\hline \multirow{2}{*}{$\begin{array}{c}\text { Micro- } \\
\text { organism }\end{array}$} & \multicolumn{1}{|c|}{ Time of incubation (days) $\rightarrow$} & 3 & 6 & 9 \\
\cline { 2 - 5 } & \multicolumn{1}{|c|}{ Product } & \multicolumn{3}{|c|}{ Yield (\%) } \\
\hline \multirow{2}{*}{ A. niger KB } & 3'-hydroxyflavon-3-yloxymethyl myristate & 53.7 & 64.8 & 69.8 \\
\cline { 2 - 5 } & Unreacted substrate & 38.2 & 24.1 & 15.5 \\
\hline \multirow{2}{*}{ A. niger MB } & 3'-hydroxyflavon-3-yloxymethyl myristate & 25.1 & 30.7 & 37.2 \\
\cline { 2 - 5 } & Unreacted substrate & 73.2 & 63.2 & 53.0 \\
\hline \multirow{2}{*}{ A. niger SBP } & 3'-hydroxyflavon-3-yloxymethyl myristate & 38.7 & 50.4 & 63.1 \\
\cline { 2 - 5 } & Unreacted substrate & 60.0 & 46.3 & 27.3 \\
\hline \multirow{2}{*}{ A. niger SBJ } & 3'-hydroxyflavon-3-yloxymethyl myristate & 22.5 & 23.7 & 24.9 \\
\cline { 2 - 5 } & Unreacted substrate & 75.9 & 70.9 & 59.8 \\
\hline \multirow{2}{*}{ A. niger 13/5 } & 3'-hydroxyflavon-3-yloxymethyl myristate & 10.1 & 20.3 & 20.5 \\
\cline { 2 - 5 } & Unreacted substrate & 87.8 & 73.2 & 70.0 \\
\hline
\end{tabular}

Table II

Biotransformation of 3-methoxyflavone (substrate added 72 hours after inoculation) - yield (\%) of product determined by HPLC

\begin{tabular}{|l|l|c|c|c|}
\hline \multirow{2}{*}{ Microorganism } & \multicolumn{1}{|c|}{ Time of incubation (days) $\rightarrow$} & \multicolumn{2}{|c|}{6} & \multicolumn{2}{|c|}{ Yield (\%) } \\
\cline { 2 - 5 } & \multicolumn{1}{|c|}{ Product } & \multicolumn{2}{|c|}{} \\
\hline \multirow{2}{*}{ A. niger KB } & 3'-hydroxyflavon-3-yloxymethyl myristate & 13.7 & 16.2 & 18.4 \\
\cline { 2 - 5 } & Unreacted substrate & 81.2 & 70.7 & 65.0 \\
\hline \multirow{2}{*}{ A. niger MB } & 3'-hydroxyflavon-3-yloxymethyl myristate & 16.3 & 16.2 & 16.2 \\
\cline { 2 - 5 } & Unreacted substrate & 80.1 & 80.0 & 78.2 \\
\hline A. niger SBP & 3'-hydroxyflavon-3-yloxymethyl myristate & 26.2 & 26.9 & 27.3 \\
\cline { 2 - 5 } & Unreacted substrate & 72.1 & 69.7 & 65.1 \\
\hline \multirow{2}{*}{ A. niger SBJ } & 3'-hydroxyflavon-3-yloxymethyl myristate & 13.3 & 15.6 & 17.2 \\
\cline { 2 - 5 } & Unreacted substrate & 80.4 & 75.1 & 70.1 \\
\hline A. niger 13/5 & 3'-hydroxyflavon-3-yloxymethyl myristate & 12.7 & 13.5 & 14.1 \\
\cline { 2 - 5 } & Unreacted substrate & 80.3 & 77.0 & 70.2 \\
\hline P. chermesinum 113 & 3'-hydroxyflavon-3-yloxymethyl myristate & 16.7 & 19.2 & 23.8 \\
\cline { 2 - 5 } & Unreacted substrate & 80.1 & 73.3 & 65.1 \\
\hline
\end{tabular}




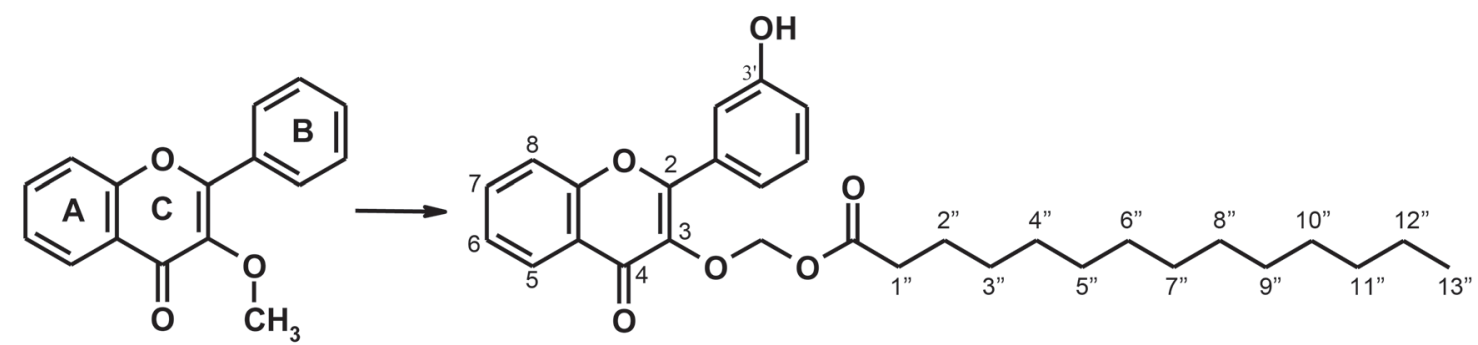

Scheme 1. Biotransformation of 3-methoxyflavone in the culture of A. niger (KB, MB, SBP, SBJ, 13/5) and P. chermesinum 113.

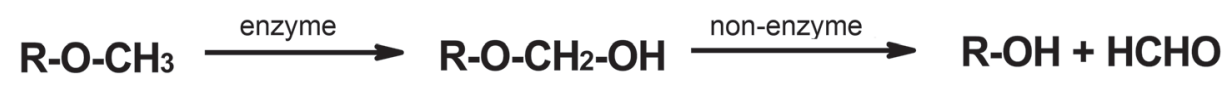

Scheme 2. Mechanism of demethylation.<smiles>CCCCCCCCCCCCCC(=O)OCOc1c(-c2cccc(O)c2)oc2ccccc2c1=O</smiles>

Scheme 3. Probable course of biotransformation of 3-methoxyflavone.

media at the time of inoculation with the microorganism. A. niger KB and A. niger SBP gave the highest yields of the product after 9 days, i.e. $69.8 \%$ and $63.1 \%$, respectively. The least efficient strain for this biotransformation was A. niger 13/5 (Table I, II).

The preparative scale biotransformation of 3-methoxyflavone was carried out using the strain of $A$. niger $\mathrm{KB}$ in a 9-day reaction. 3'-Hydroxyflavon-3-yloxymethyl myristate was isolated in $65 \%$ yield (Scheme 1) and identified by ${ }^{1} \mathrm{H}$ NMR and ${ }^{13} \mathrm{C}$ NMR. In the ${ }^{1} \mathrm{H}$ NMR spectrum the signal of the substrate methoxyl group at C-3 $(\delta=3.81 \mathrm{ppm})$ disappeared and a two proton singlet at $\delta=5.22 \mathrm{ppm}$ attributed to a $-\mathrm{O}-\mathrm{CH}_{2}-\mathrm{O}$ - group appeared. Seven new signals integrating for a total of 24 protons and a singlet of $3 \mathrm{H}$ at $\delta=0.86 \mathrm{ppm}$ indicate the presence of a 13-carbon alkyl chain of a saturated fatty acid (myristic acid) bonded at C-3 of the flavone by means of the ester bond. The ester carbonyl group is confirmed by the signal at $\delta=180.8 \mathrm{ppm}$ in the ${ }^{13} \mathrm{C}$ NMR. The presence of a hydroxyl group in the B-ring was proved by the new one-proton singlet at $\delta=7.91 \mathrm{ppm}$ which was not present in the spectrum of the substrate. The location of the hydroxyl group was determined by analyzing the shape and chemical shift of the B-ring protons. The 2' and 6' protons and the 4' and 5' protons are nonequivalent in the ${ }^{1} \mathrm{H}$ NMR of the product. In the ${ }^{13} \mathrm{C}$ NMR the C- 3 ' signal is shifted from $\delta=129.2 \mathrm{ppm}$ for the substrate to $\delta=151.0 \mathrm{ppm}$ for the product.

The mechanism of oxidative $O$-demethylation of methyl ethers by cytochrome $\mathrm{P} 450$ proposed by Watanabe is presented in Scheme 2 (Watanabe et al., 1982).

In the biotransformation of 3-methoxyflavone catalyzed by the strains of Aspergillus and Penicillium the intermediate hemiacetal is presumably esterified with myristic acid present in the cultivation mixture. Miristic acid is produced by the strains of Aspergillus. The presence of considerable myristic acid has been observed 
in conidiophores of A. flavus (Budínská et al., 1981) in the cells of A. ochraceus (Chavant and Sandolle, 1977) and in the cells of A. niger (Parang et al., 1996).

The first step of enzymatic oxidation of 3-methoxyflavone resembles metabolism of methoxy derivatives in mammals. The reaction is probably catalyzed by the fungal monooxygenases of cytochrome P-450. The proposed mechanism of the biotransformation is presented in Scheme 3. Earlier research on microbial transformations of monosubstituted flavones with methoxyl groups in the A-ring (Kostrzewa-Susłow et al., 2012) indicate that the strains of Aspergillus and P.chermesinum used for this study perform non-typical demethylation which ends with introduction of myristic acid in the favourable C-3 flavone position.

Conclusions. Transformation of 3-methoxyflavone in the cultures of $A$. niger (KB, MB, SBP, SBJ, 13/5) and P.chermesinum 113 is a two-step process involving enzymatic oxidation of both the methoxyl group and the B-ring of the flavone and then esterification of the $-\mathrm{O}-\mathrm{CH}_{2}-\mathrm{OH}$ group with myristic acid. The highest yield of transformation was achieved for the strain A. niger $\mathrm{KB}$, when the substrate was added at the time of inoculation.

\section{Acknowledgements}

This work was financed by the project "Biotransformations for pharmaceutical and cosmetics industry" No. POIG.01.03.01-00$158 / 09$, which is partly-financed by the European Union within the European Regional Development Fund for the Innovative Economy"

\section{Literature}

Budínská O., V. Kubin, J. Franĕk, J. Julák and J.A. Panos. 1981. A lipopolysaccharide from Aspergillus flavus conidia. Folia Microbiol. 26: 212-216.

Buisson D., J. Quintin and G. Lewin. 2007. Biotransformation of polymethoxylated flavonoids: access to their 4-O-demethylated metabolites. J. Nat. Prod. 70: 1035-1038.

Chavant L. and M. Sandolle. 1977. Les lipids de deux moisissures: Mucor mucedo et Aspergillus ochraceus se dèveloppant sur meme milieu. Physiol. Vèg. 15: 209-213.

Das S. and J.P.N. Rosazza. 2006. Microbial and enzymatic transformations of flavonoids. J. Nat. Prod. 69: 499-508.

Herath W., J.R. Mikell and I.A. Khan. 2009. Microbial metabolism. Part 10. Metabolites of 7,8-dimethoxyflavone and 5-methoxyflavone. Nat. Prod. Res. 23: 1231-1239.

Kostrzewa-Susłow E., J. Dmochowska-Gładysz, T. Janeczko, K. Środa, K. Michalak and A. Palko. 2012. Microbial transformations of 6- and 7-methoxyflavone in Aspergillus niger and Penicillium chermesinum cultures. Z. Naturforsch. 67c: 411-417.

Kostrzewa-Susłow E. and T. Janeczko. 2012a. Microbial transformations of 7-hydroxyflavanone. The Scientific World Journal. 2012:1-8. doi: 10.1100/2012/254929.

Kostrzewa-Susłow E. and T. Janeczko. 2012b. Microbial transformations of 7-methoxyflavanone. Molecules. 17: 14810-14820.

Parang K., E.E. Knaus, L.I. Wiebe, S. Sardari, M. Daneshtalab and F. Csizmadia. 1996. Synthesis and antifungal activities of myristic acid analogs. Archiv der Pharmazie. 329: 475-482.

Wang A., F. Zhang, L. Huang, X. Yin, H. Li, Q. Wang, Z. Zeng and T. Xie. 2010. New progress in biocatalysis and biotransformation of flavonoids. J. Med. Plants Res. 4: 847-856.

Watanabe Y., S. Oae and T. Iyanagi. 1982. Mechanisms of enzymatic $S$-oxygenation of thioanisole derivatives and $O$-demethylation of anisole derivatives promoted by both microsomes and a reconstituted system with purified cytochrome P-450. Bull. Chem. Soc. Jpn. 55: 188-195. 